\title{
Comparison of Mathematical Methods to Obtain Concentration and Temperature of Newtonian Fluids in Tubular Reactors
}

\author{
Diego Alves de Miranda, Renato Cristofolini, Emerson José Corazza, \\ Gilson João dos Santos, Claiton Emilio do Amaral \\ Department of Mechanical Engineering, University of the Region of Joinville-UNIVILLE, Joinville, Brazil \\ Email: diegoalves_klx@hotmail.com
}

How to cite this paper: de Miranda, D.A., Cristofolini, R., Corazza, E.J., dos Santos, G.J. and do Amaral, C.E. (2018) Comparison of Mathematical Methods to Obtain Concentration and Temperature of Newtonian Fluids in Tubular Reactors. Open Access Library Journal, 5: e4329.

https://doi.org/10.4236/oalib.1104329

Received: January 12, 2018

Accepted: February 9, 2018

Published: February 12, 2018

Copyright $\odot 2018$ by authors and Open Access Library Inc.

This work is licensed under the Creative Commons Attribution International License (CC BY 4.0).

http://creativecommons.org/licenses/by/4.0/

\begin{abstract}
In several areas of engineering, it is possible to put real problems in mathematical functions; when we represent a problem with variables in the form of function, we were able to extract various information from it. This paper compared two different mathematical methods, being the finite difference method and the Fourth Order Range-Kutta method, to analyze the concentration and temperature of the water flow inside a tubular reactor. These results were compared with the analytical and experimental results of the problem, demonstrating that the Fourth Order Range-Kutta method was more advantageous than the finite difference method.
\end{abstract}

\section{Subject Areas}

Computer Engineering, Experimental Physics, Fluid Mechanics, Mathematical Analysis

\section{Keywords}

Tubular Reactor, Mathematical Methods, Finite Differences, Runge-Kutta

\section{Introduction}

The Tubular Reactor describes chemical reactions in continuous flow systems, so that the main reactor variables, such as reactor dimensions, can be estimated [1] [2]. A fluid passing through a tubular reactor can be modeled by flowing through the reactor as a series of infinitely fine coherent "pistons," each with a uniform composition, moving in the axial direction of the reactor, each piston having a different composition from the before and after it [3]. 
A differential equation is called an equation in which the unknown is a function, and has a relation with the derivatives of this function [4]. Differential equations are used in mathematical modeling problems and when a function depends on a single independent variable, they are called ordinary differential equations [4] [5] [6]. Several industrial problems can be mathematically described by Differential Equations as they represent some physical variations that describe [7]. Ordinary differential equations, which are those equations involving an unknown function and their ordinary derivatives, are of great interest in the exact sciences and in other areas of human knowledge, since many laws and physical relations can be formulated mathematically by means of a differential equation [8]. There are several methods for analytically solving an ODE, however, it is not always possible to obtain an analytical solution or it becomes very complex such a resolution [9]. In this case, the numerical methods are an outlet to find a solution as close as you want [10].

In this context, this paper had the objective of comparing two mathematical methods and comparing them with the analytical and experimental solution.

\section{Materials and Methods}

For experimental analysis, a tubular glass reactor was used, with 10 thermocouples of type J to measure the temperature and 10 Capacitive density transmitters to measure the concentration. The reactor of approximately $100 \mathrm{~mm}$ internal diameter and $1000 \mathrm{~mm}$ in length can best be observed in Figure 1 .

To do the numerical analysis of the experiment, we first have to consider the differential equation capable of confronting the resulting physical phenomena. A positioning scheme of the apparatus installed in the reactor can best be seen in Figure 2.

Consider a jacketed tubular reactor conducting a second order exothermic chemical reaction $(2 \mathrm{~A} \rightarrow \mathrm{B})$. The diagram of this reactor can be better observed in the Figure 3.

The initial concentration of $\mathrm{H}_{2} \mathrm{O}$ is $10 \mathrm{kmol} / \mathrm{m}^{3}$. Assuming that the reactor

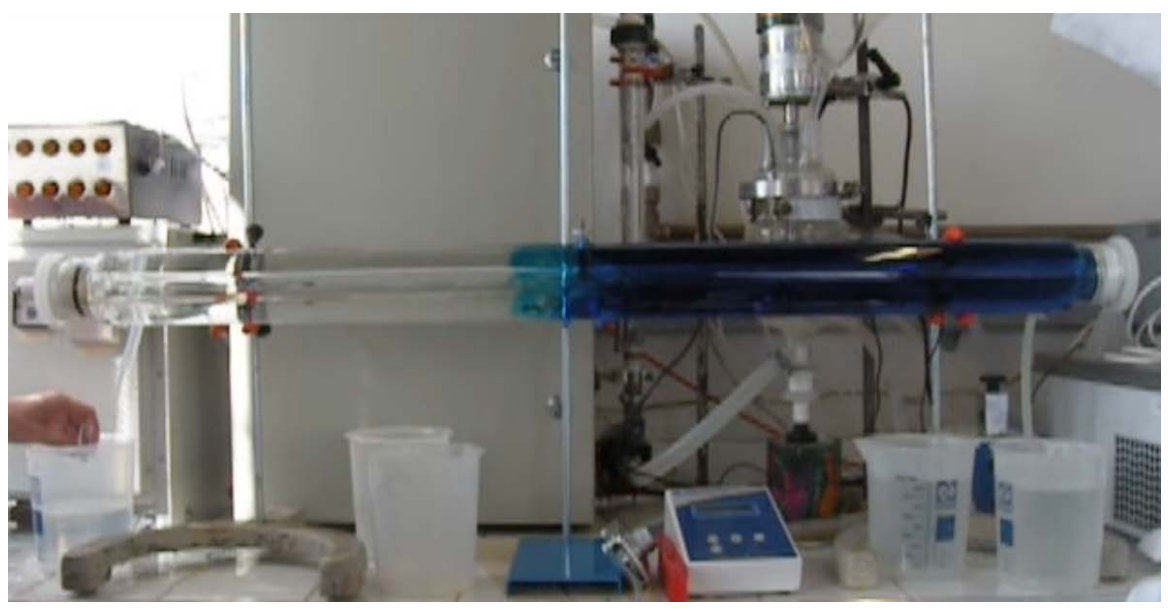

Figure 1. Glass Tubular Reactor. 

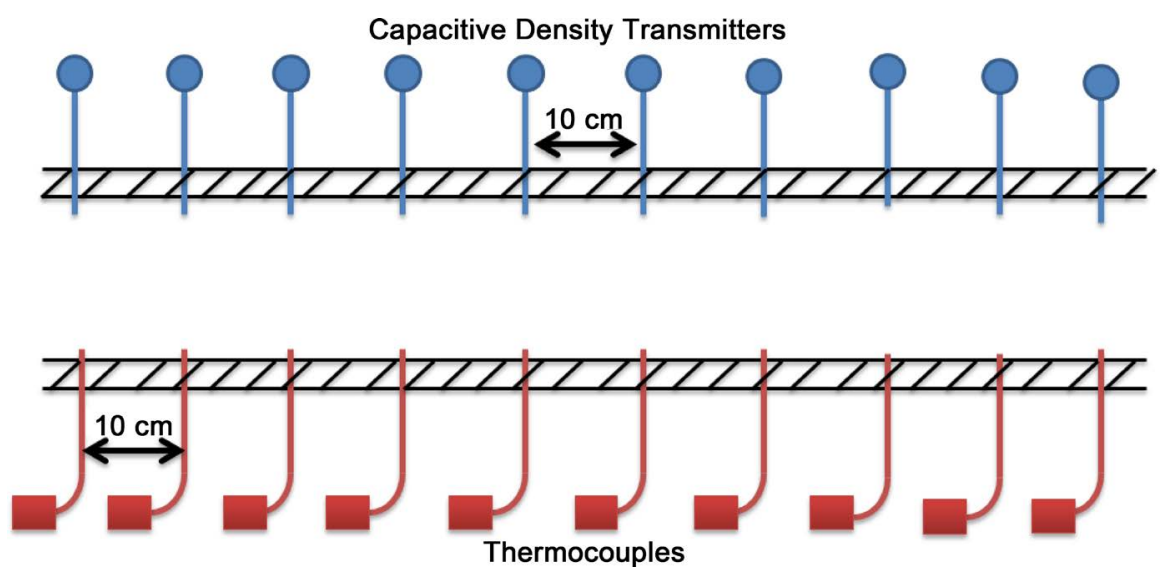

Figure 2. Device positioning diagram.

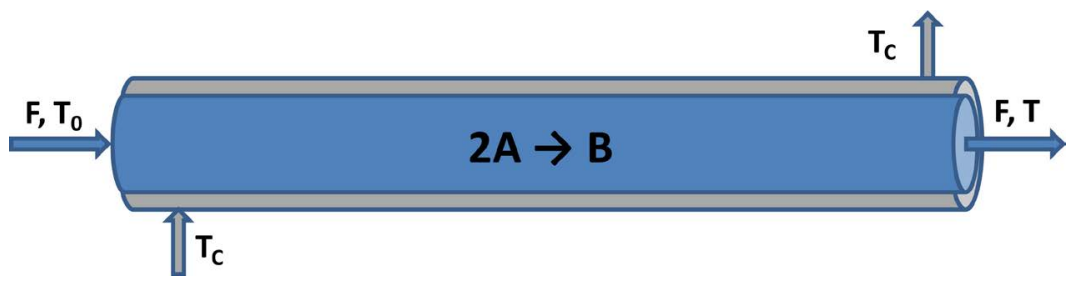

Figure 3. Representation of the Tubular Reactor.

jacket temperature is constant, and that it does not lose heat to the environment, the mathematical model that describes the variation of reagent concentration $A$ and the reactor internal temperature throughout the equipment is given by the following Equations ((1) and (2)) differentials successively:

$$
\begin{aligned}
& \frac{\mathrm{d} C_{A}}{\mathrm{~d} x}=-k_{0} \cdot \mathrm{e}^{-\frac{E_{A}}{R \cdot T}} \cdot C_{A}^{2} \cdot \frac{A \cdot \rho}{F} ; C_{A 0}(0)=10 \mathrm{kmol} / \mathrm{m}^{3} \\
& \frac{\mathrm{d} T}{\mathrm{~d} x}=-\frac{U \cdot 2 \pi \cdot R_{R}}{F \cdot C p} \cdot\left(T-T_{C}\right)+k_{0} \cdot \mathrm{e}^{-\frac{E_{A}}{R \cdot T}} \cdot C_{A}^{2} \cdot \frac{A \cdot\left(-\Delta H_{R}\right)}{F \cdot C p}
\end{aligned}
$$

As the fluid used in this study was water, recurrent water parameters were used at $295 \mathrm{~K}$. These values can be better observed in Table 1.

To solve numerically the system of differential equations 1 and 2, applying the Finite Differences Method and the Runge-Kutta Method, we have the following resolution equations:

$$
\begin{aligned}
\frac{\mathrm{d} C_{\mathrm{A}}}{\mathrm{d} x}=-(50) \cdot \mathrm{e}^{\frac{-30000}{8.314 \cdot T}} \cdot C_{A}^{2} \cdot \frac{\pi \cdot(0.050)^{2} \cdot 1000}{0.05} \\
\frac{\mathrm{d} T}{\mathrm{~d} x}=-\frac{(100) \cdot 2 \pi \cdot(0.0127)}{0.05 \times 4187} \cdot(T-315) \\
+50 \cdot \mathrm{e}^{\frac{-30000}{8.314 \cdot T}} \cdot C_{A}^{2} \cdot \frac{\pi \cdot(0.0127)^{2} \cdot\left[-\left(-1 \times 10^{-7}\right)\right]}{0.05 \times 4187}
\end{aligned}
$$

The method of finite differences is proposed by Equation (5):

$$
f\left(x_{0}, u_{0}\right)=\frac{y_{1}-y_{0}}{h} \rightarrow y_{1}=y_{0}+h f\left(x_{0}, y_{0}\right)
$$


Table 1. Water variables in the tubular reactor.

\begin{tabular}{ccc}
\hline Variables & Values & Units \\
\hline$F$ & 0.05 & $\mathrm{~kg} / \mathrm{s}$ \\
$\rho$ & 1000 & $\mathrm{~kg} / \mathrm{m}^{3}$ \\
$R_{R}$ & 0.05 & $\mathrm{~m}$ \\
$k_{0}$ & 50 & $\mathrm{~m}^{3} / \mathrm{kmol} \cdot \mathrm{s}$ \\
$R$ & 8.314 & $\mathrm{~J} / \mathrm{mol} \cdot \mathrm{K}$ \\
$E_{A}$ & 30,000 & $\mathrm{~J} / \mathrm{mol}$ \\
$\Delta H$ & $-1 \times 10^{-7}$ & $\mathrm{~J} / \mathrm{mol}$ \\
$U$ & 100 & $\mathrm{~J} / \mathrm{m}^{2} \cdot \mathrm{s} \cdot \mathrm{K}$ \\
$L$ & 1 & $\mathrm{~m}$ \\
$C P$ água & 4.187 & $\mathrm{KJ} / \mathrm{kg} \cdot \mathrm{K}$ \\
$T_{0}$ & 295 & $\mathrm{~K}$ \\
$T_{c}$ & 315 & $\mathrm{~K}$ \\
\hline
\end{tabular}

Implementing Equations ((3) and (4)), which are the concentration and temperature equations, we obtain Equations ((6) and (7)) successively:

$$
\begin{gathered}
\frac{\mathrm{d} C_{\mathrm{A}}}{\mathrm{d} x}=\frac{C A_{1}-C A_{0}}{h} \rightarrow C A_{1}=C A_{0}+h \frac{\mathrm{d} C_{\mathrm{A}}}{\mathrm{d} x} \\
\frac{\mathrm{d} T}{\mathrm{~d} x}=\frac{T_{1}-T_{0}}{h} \rightarrow T_{1}=T_{0}+h \frac{\mathrm{d} T}{\mathrm{~d} x}
\end{gathered}
$$

The fourth order Runge-Kuta method is defined by the following equations:

$$
\begin{gathered}
y_{1}=y_{0}+\left[\frac{1}{6}\left(k_{1}+2 k_{2}+2 k_{3}+k_{4}\right)\right] h \\
k_{1}=f\left(x_{0}, y_{0}\right) \\
k_{2}=f\left(x_{0}+\frac{1}{2} h, y_{0}+\frac{1}{2} h k_{1}\right) \\
k_{3}=f\left(x_{0}+\frac{1}{2} h, y_{0}+\frac{1}{2} h k_{2}\right) \\
k_{3}=f\left(x_{0}+h, y_{0}+h k_{3}\right)
\end{gathered}
$$

To perform these calculations, steps $10 \mathrm{~cm}, 5 \mathrm{~cm}$ and $1 \mathrm{~cm}$ were used to know which of these interactions converges faster to solve the system.

\section{Results and Discussion}

Applying the mathematical and experimental methods, a $10 \mathrm{~cm}$ step was initially used to perform the calculations. The results of concentration and temperature can be seen in Figure 4.

Analyzing Figure 4(a), it is possible to notice that the analytical method is the closest to the experimental measurements of concentration. The finite difference method came close to the analytical solution, and the Runge-Kutta method ob- 
tained a greater discrepancy than the others. In Figure 4(b), it was noted that the finite difference method were obtained at temperatures closer to the experimental ones than the analytical method. Again the Runge-Kutta Method was the method that obtained a larger discrepancy considering the experimental part.

In the next analysis, the same parameters were compared with a step of $5 \mathrm{~cm}$. These results can be seen in Figure 5 .

Similar to Figure 5(a), the analytical method still comes closest to the experimental concentration values. The Runge-Kutta method demonstrates values well out of reality. However, this method is approaching the experimental results smoothly. In the temperature values, results similar to those of Figure 4(b) were also obtained. In the last battery of results, a calculation with the step of $1 \mathrm{~cm}$ was carried out. These results can be better observed in Figure 6 .

The concentration results of Figure 6(a) demonstrate that all methods

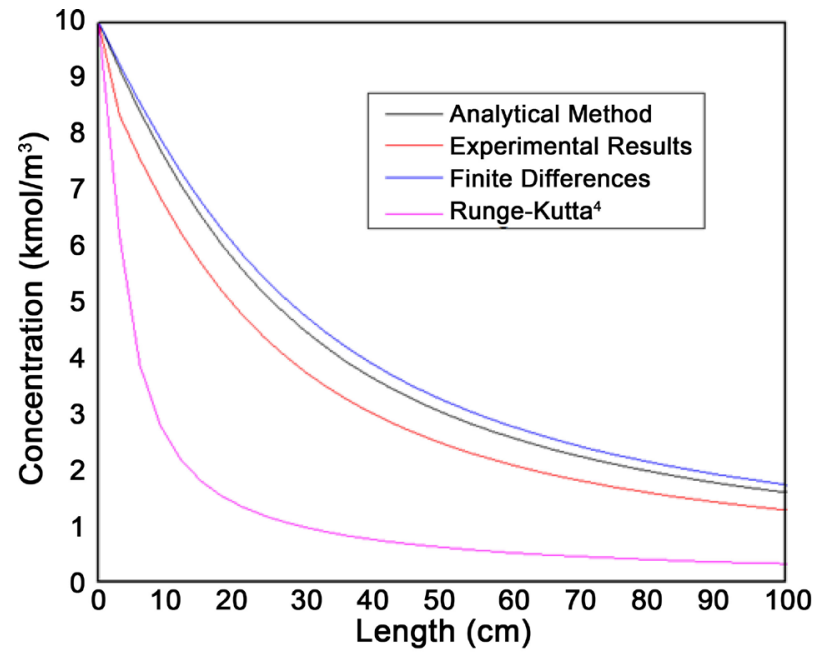

(a)

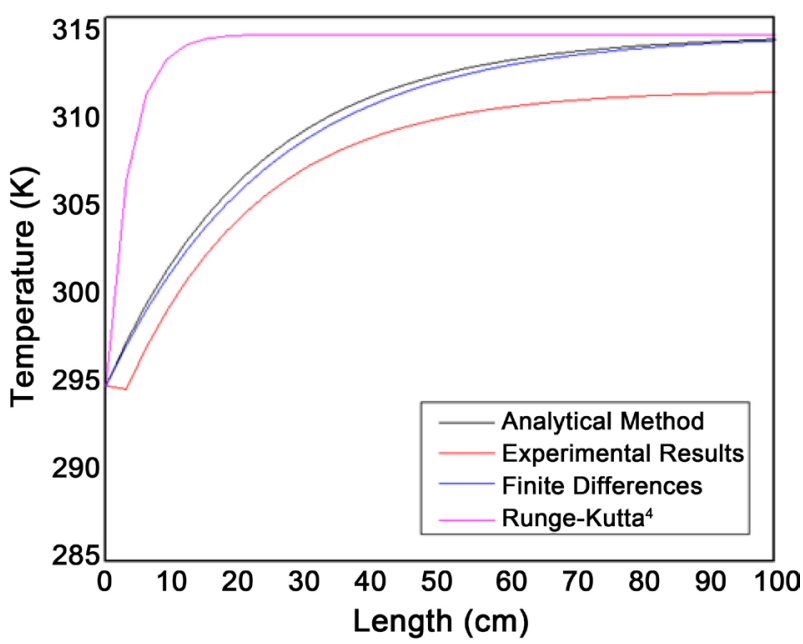

(b)

Figure 4. Numerical, Analytical and Experimental Results Along the Reactor With $10 \mathrm{~cm}$ pitch. (a) Concentration, (b) Temperature. 


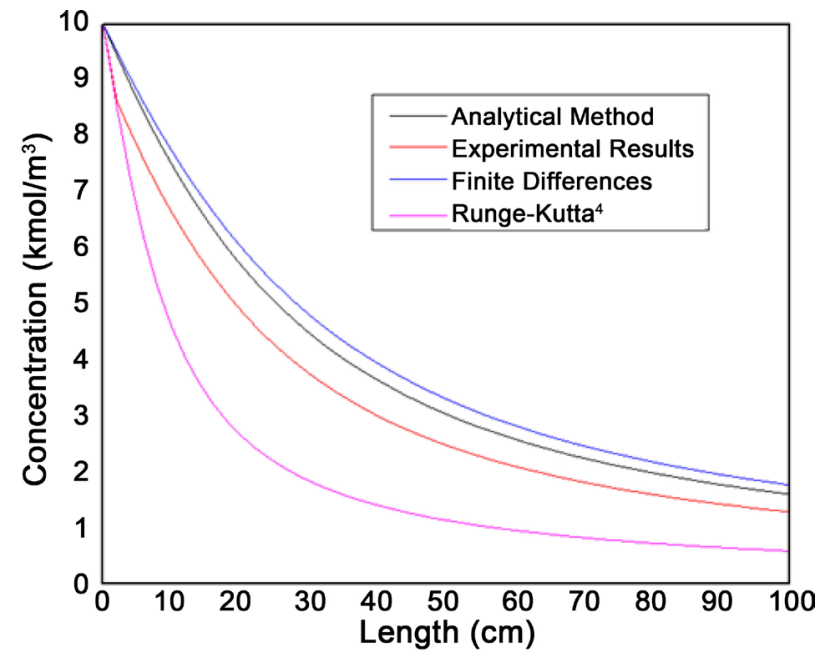

(a)

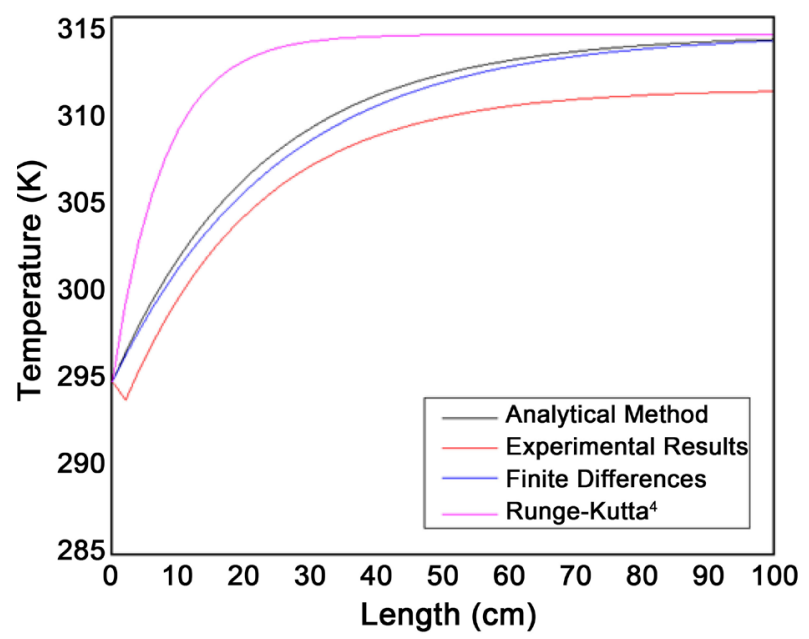

(b)

Figure 5. Numerical, Analytical and Experimental Results Along the Reactor with $5 \mathrm{~cm}$ pitch. (a) Concentration; (b) Temperature.

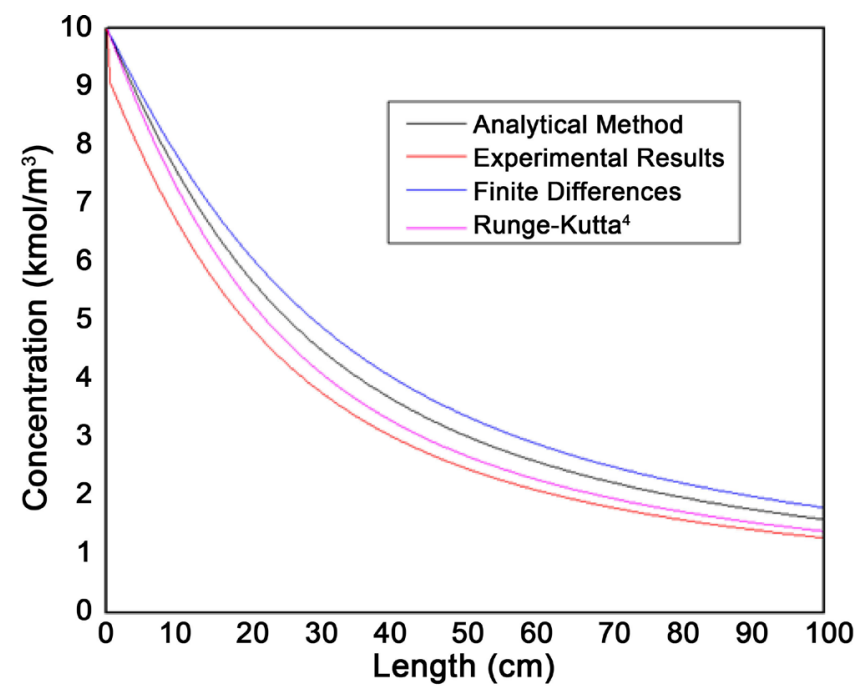

(a) 


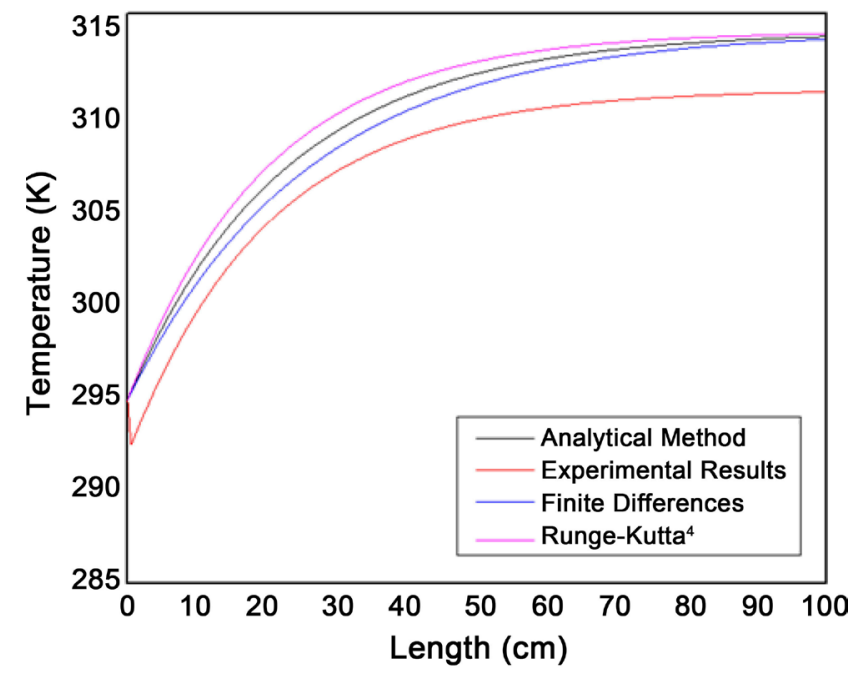

(b)

Figure 6. Numerical, Analytical and Experimental Results Along the Reactor With $1 \mathrm{~cm}$ pitch. (a) Concentration; (b) Temperature.

approximate the experimental results. However, the Runge-kutta Method is now the one that gets values closer to reality, almost touching the same curve. In the results of temperature, the methods end up leaving the curve route at the end of the course of the reactor. And the curve that comes closest to reality is that of finite differences.

\section{Conclusions}

Analyzing the methods by looking at the graphs and calculations performed, we realize that the smaller the step used, the more precise the concentration and temperature values arrive, because with the big steps, the curves go out a little bit of reality and change the concentration drastically and increase the temperature beyond the final length.

The method that proved most efficient in wide steps was the finite difference method, and as the steps were narrowing the Runge-Kutta method began to show smoother and more accurate curves.

\section{References}

[1] Wachs, A., Clermont, J.R. and Khalifeh, A. (2002) Computations of Non-Isothermal Viscous and Viscoelastic Flows in a Brupt Contractions Using a Finite Volume Method. Engineering Computations, 19, 874-901.

[2] Berlitz, T. and Matschke, G. (2004) Interior Airflow Simulation in Railway Rolling Stock. Research and Technology Centre of the Deutsche Bahn AG, Division for Aerodynamics and Airconditioning.

[3] Yongson, O., Irfan, A.B., Zainala, Z.A. and Narayana, P.A.A. (2007) Airflow Analysis in an Air Conditioning Room. Building and Environment, 42, 1531-1537. https://doi.org/10.1016/j.buildenv.2006.01.002

[4] Mikielewicz, D.P., Shehata, A.M., Jackson, J.D. and McEligot, D.M. (2002) Temperature, Velocity and Mean Turbulence Structure in Strongly Heated Internal Gas 
Flows. International Journal of Heat and Mass Transfer, 45, 4333-4352. https://doi.org/10.1016/S0017-9310(02)00119-9

[5] Huang, P.G., Coleman, G.N. and Bradshaw, P. (1995) Compressible Turbulent Channel Flows: DNS Results and Modelling. Journal of Fluid Mechanics, 305, 185-218. https://doi.org/10.1017/S0022112095004599

[6] Satake, S.I., Kunugi, T., Shehata, A.M. and McEligot, D.M. (2000) Direct Numerical Simulation for Laminarization of Turbulent Forced Gas Flows in Circular Tubes with Strong Heating. International Journal of Heat and Fluid Flow, 21, 526-534. https://doi.org/10.1016/S0142-727X(00)00041-2

[7] Kays, W., Crawford, M. and Weigand, B. (2005) Convective Heat and Mass Transfer. 4th Edition, McGraw-Hill, New York.

[8] Dukler, A.E. and Hubbard, M.G. (1975) A Model for Gas-Liquid Slug Flow in Horizontal and Near Horizontal Tubes. Industrial \& Engineering Chemistry Fundamentals, 14, 337-347. https://doi.org/10.1021/i160056a011

[9] Smith, I.E., Nossen, J. and Unander, T.E. (2013) Improved Holdup and Pressure Drop Predictions for Multiphase Flow with Gas and High Viscosity Oil. BHR Group.

[10] Burchard, H., Deleersnijder, E. and Meister, A. (2003) A High-Order Conservative Patankar-Type Discretisation for Stiff Systems of Production-Destruction Equations. Applied Numerical Mathematics, 47, 1-30. 